\title{
Developing Place-Based, Culturally Sustaining Earth Science Teachers: Strategies To Integrate Traditional Ecological Knowledge Into Geoscience Instruction
}

\section{Pauline W. U. Chinn}

\section{University of Hawai 'i at Manoa}

\#274-6

Geological Society of America Annual Meeting Indianapolis, Indiana, USA

4-8 November, 2018
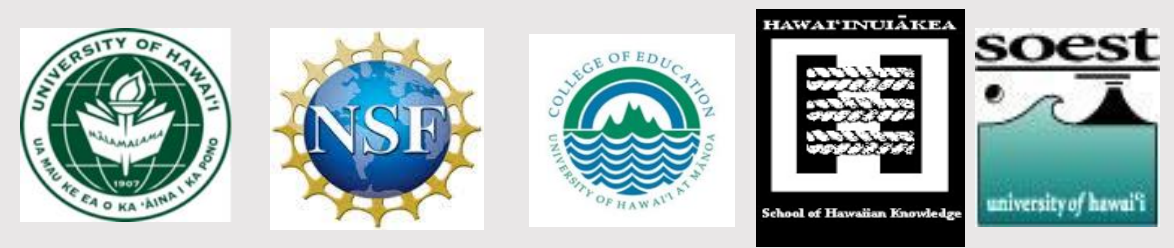


\section{Research Questions}

What is the evidence that PD strategies support:

1. teacher agency, defined as creating and teaching culturally sustaining, place-based earth science lessons that support Native Hawaiian students' learning and engagement?

2. capacity building of teachers able to create and teach these earth science lessons?

Ahupua‘a, Kamehameha Schools-Bishop Estate.

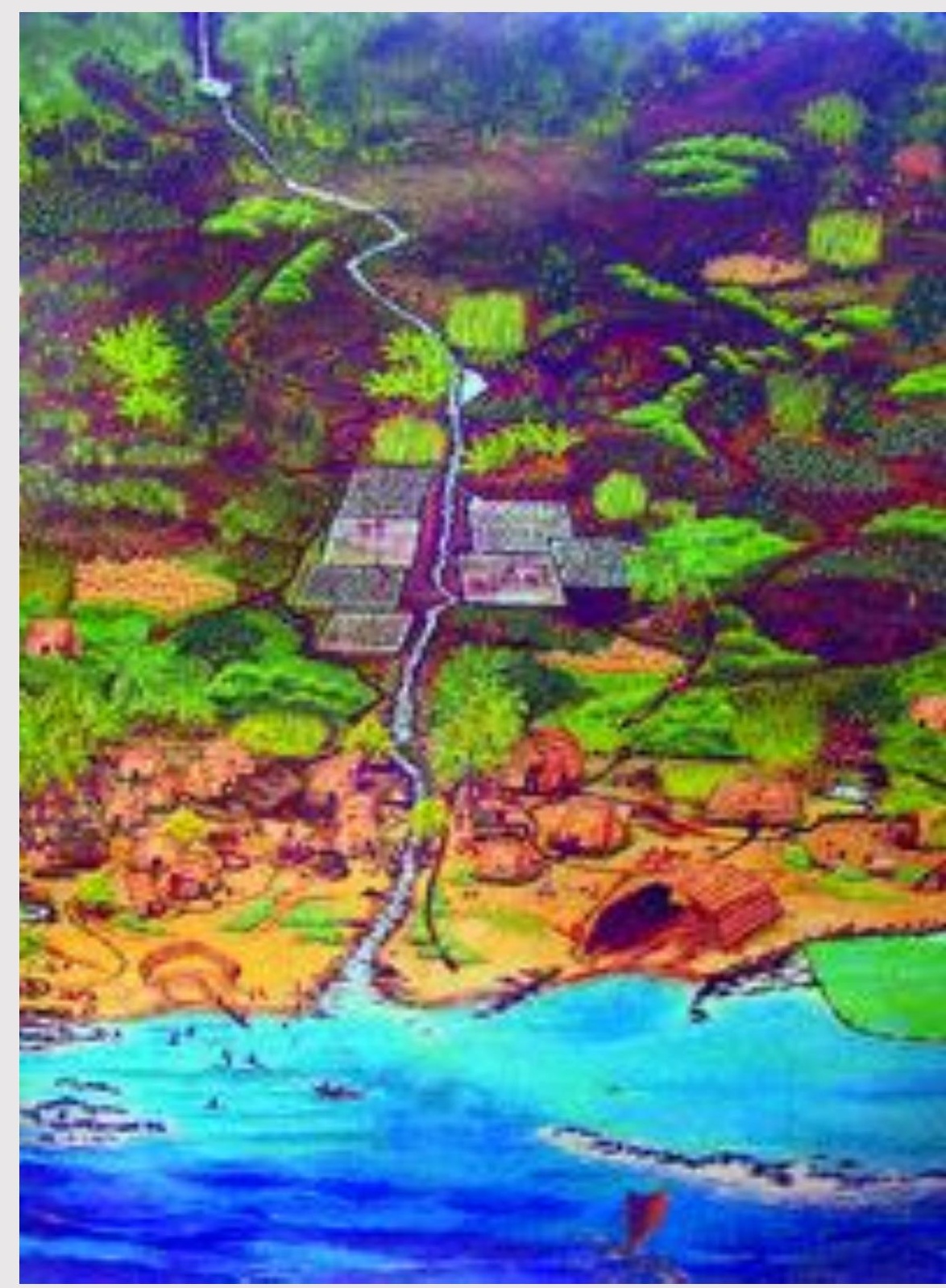




\section{Models of Ahupua'a}

Streams fed by mountain rainfall

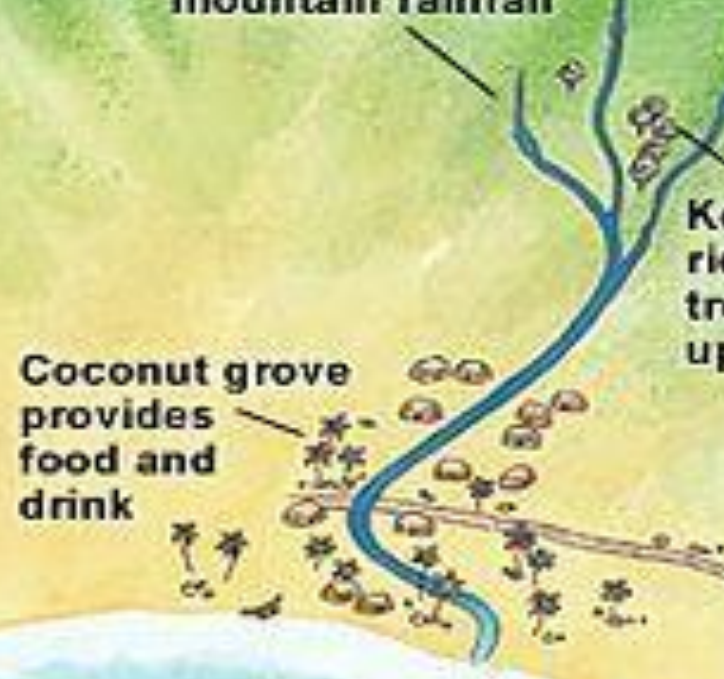

Koa trees on ridges, kukui trees in moister upper ravines
Water diverted to narrow taro lo'i that fit into the upper valley

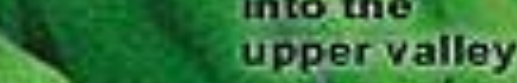

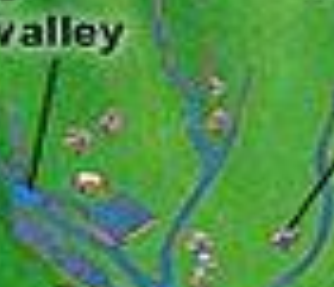

Water leaving the $10^{\circ} \mathrm{i}$ retums to the main stream 6.2

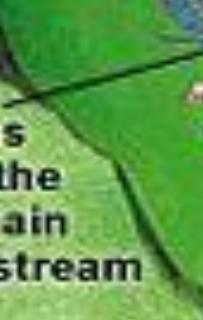

Swift streams carry rainwater from ridges down steep slopes

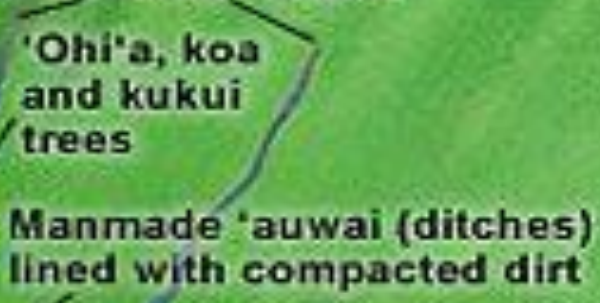

Leeward

fishing village "osol

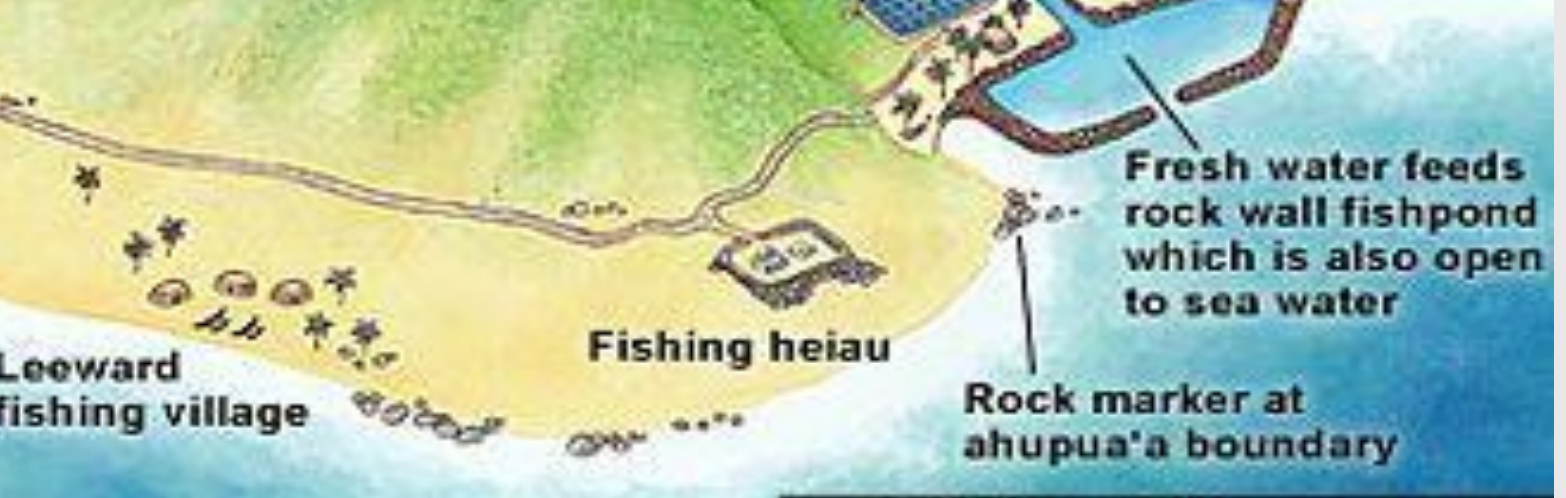

ow $\cdots$
Broader taro lo'i fill the wider valley mouth

visit HawaitHistory.com

800 CE Polynesians arrive 28 plants, dog, pig, chicken, rat 1300 CE unique to Hawai'i: ahupua'a ridge to reef, mauka-makai, sustainable geopolitical resource units. 
Teacher Expertise/Agency: Ability to Intersect Three Knowledge Domains

Domains of placebased knowledge (Sewell, 1992):

1. Science

2. Place-based resources

3. Knowledge of culture, values, practices, metaphors.



Figure 1. P Chinn 


\section{Teachers' challenges}

- Low knowledge of cultural values, practices, places, language (Moll et al, 1992)

- Limited knowledge of place-based, Hawaii-relevant science;

- Weak place-based knowledge \& networks with local science and cultural


experts. 
Barriers to integration of western science

\section{and Traditional Ecological}

Knowledge/Indigenous/Sustainability

\section{Science}

1. Western categories: Dewey Decimal Classification System 1876

2. "Pure" science (500) vs. science-in-use (600) TEK/Indigenous/Sustainability Science

3. Instruction in Hawaiian forbidden 1896-1978

4. Academic tracking $\mathrm{K}-16$

5. Policies: NCLB 2001-15, high stakes testing

6. Teachers: lack Hawai'i/Pacific sciences 
Traditional Ecological Knowledge

The evolving body of knowledge acquired by indigenous peoples through direct contact with the environment evolving by adaptive processes about the relationship of living beings (human and non-human) encompassing a world view including ecology, spirituality, human and animal relationships.

U.S. Fish \& Wildlife Service (n.d.)
Indigenous Science:

System of thought, action and orientation applied by an Indigenous people through which they interpret how Nature works in 'their place' including classifying, inferring, questioning, observing, interpreting, predicting, monitoring, problem solving, and adapting. Perceives from a 'high context " view including all relational connections in its considerations (Cajete 1999). 


\section{Participants}

EDCS 640P(S) Seminar Place-based Education, Sustainability

Two classes, 33 educators

- 2016-17: 15/19 completed

- 2017-18: 13/14 13/14 completed

- Formal and informal STEM educators

- Two from American Samoa

Right: June 2017 Immersion, Hilo, Hawai'i

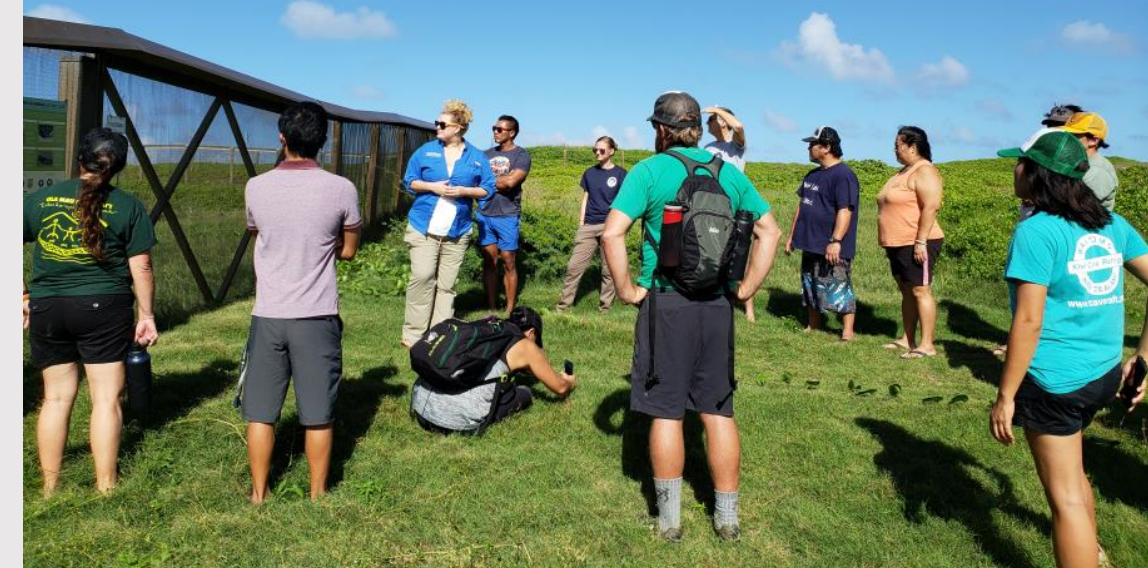

Above: Seabird translocation: James Campbell Wildlife Refuge, O’ahu.




Strategies to develop culturally sustaining, placebased Earth Science curricula

1. Personal reflection on place, learning, and identity

2. Community-based PD

3. Community/participatory mapping

4. Curricular mapping: NGSS, HĀ

5. Intersect place, culture, STEM

6. Academic year to teach and assess

7. Place-based immersions

8. Teachers host at sites: kīpuka on Mauna Loa

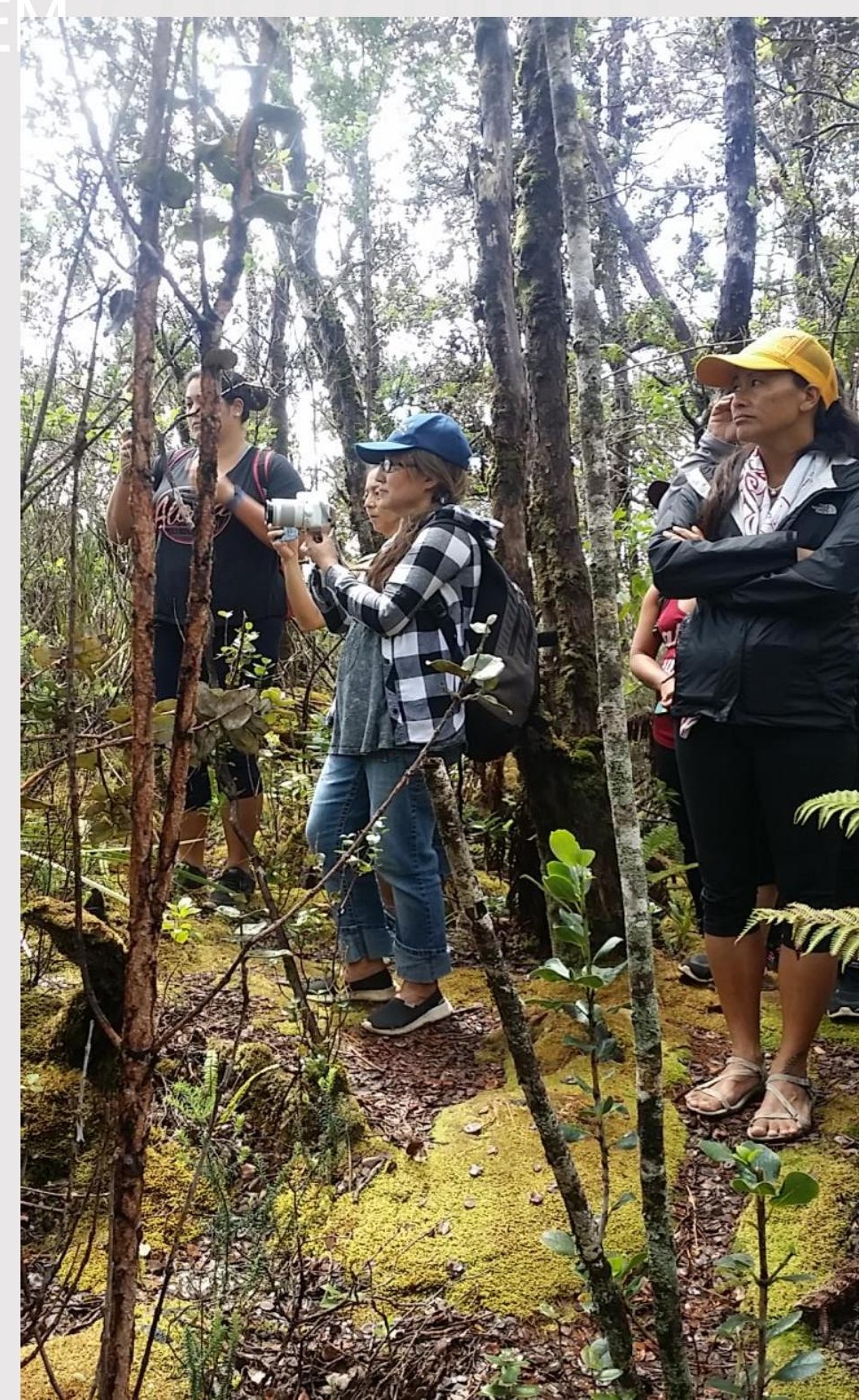


Community and curricular mapping:

Timelines \& techniques (Georeferencing)

Case Study: Fall 2015 Wai'anae Intermediate: rural, high poverty, majority Native Hawaiian, 38\% chronic absenteeism, 25\% teacher turnover/yr.

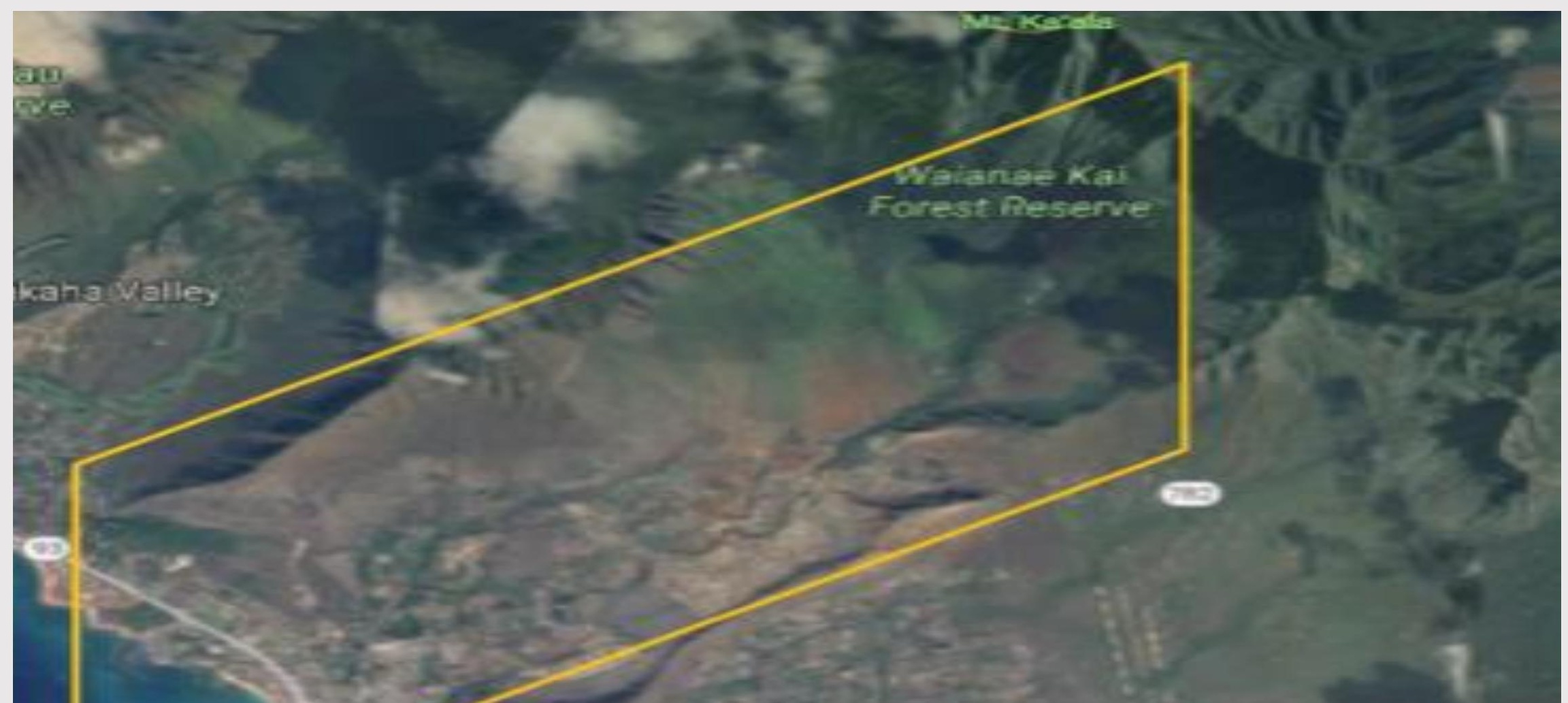




\section{Steps to transforming Science Curriculum}

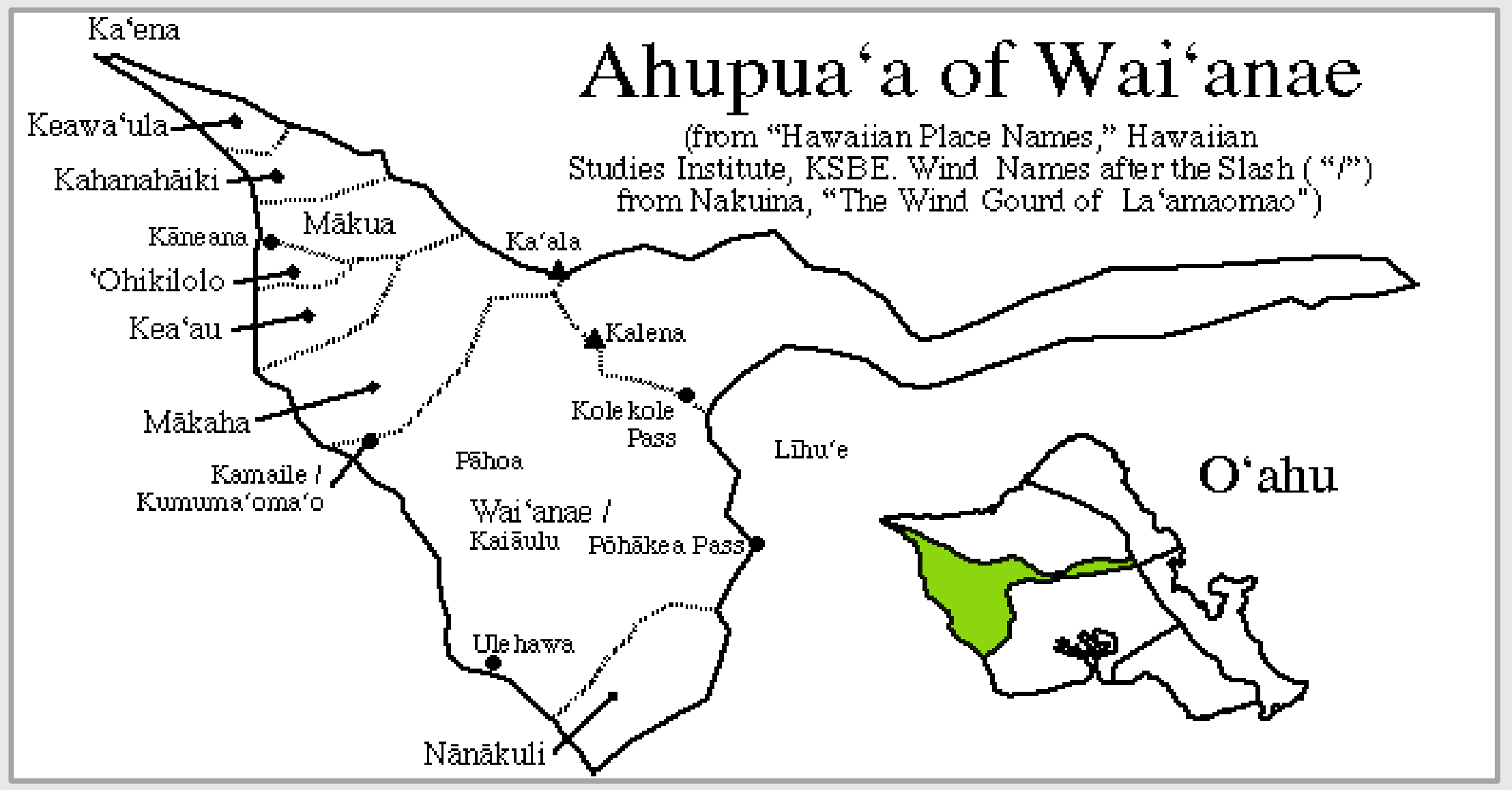

Indigenizing: Ola o Wai'anae i ka makani Kaiāulu. Wai'anae is made comfortable by the Kaiāulu breeze. (Modified from slide by Kekaha Spencer.) 


\section{Ka'ena Point - Culture, Place, Practice, *Partners}

Ka'ena Pt Qöhaku o Kaua'i

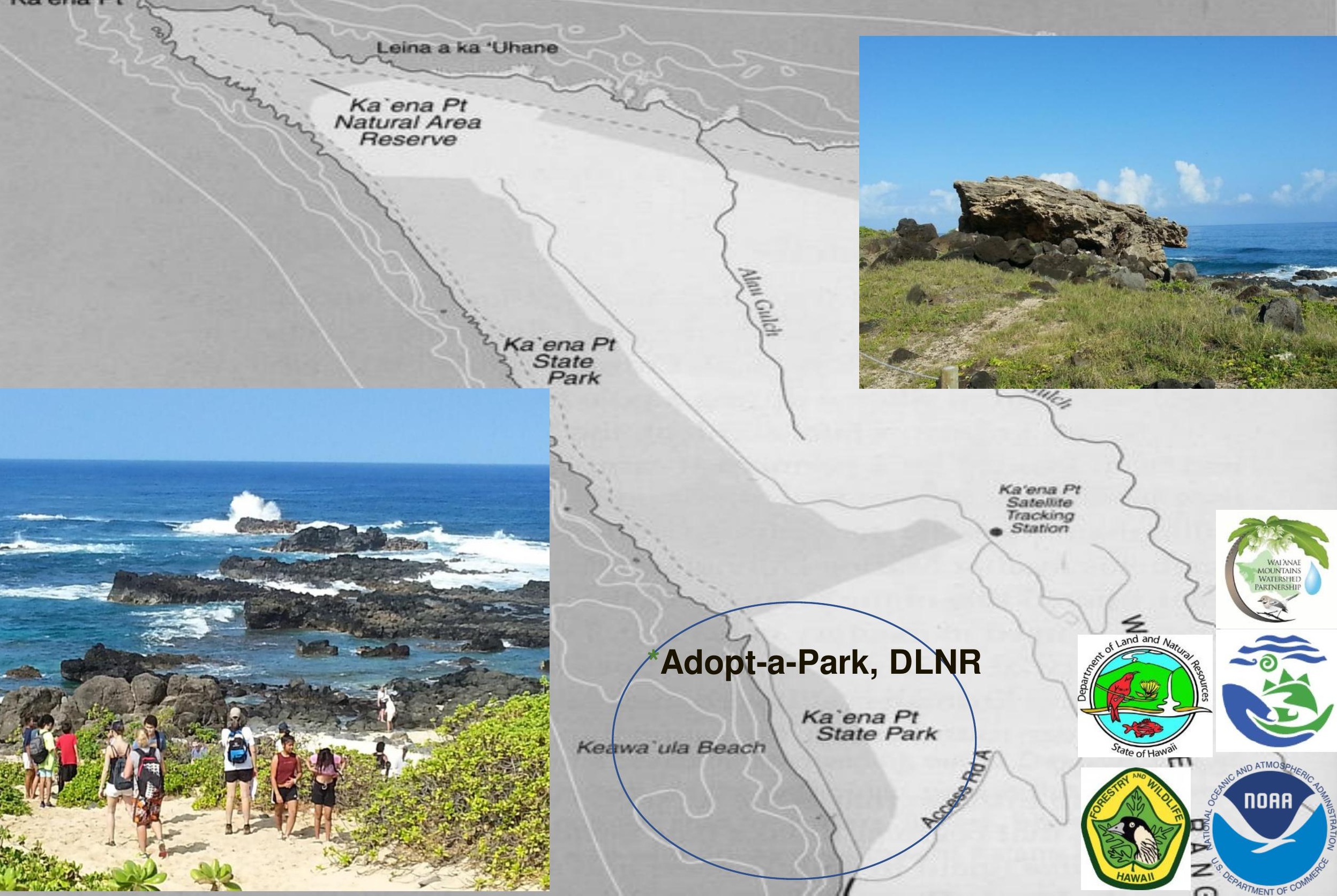




\section{Wai'anae Ahupua'a Models (courtesy Brigitte Russo)}

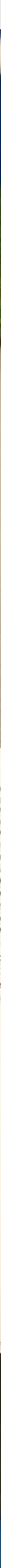


O Ka-ala, kuahiwi mauna kehau, Ke opú mai la, la, i Ka-maóha; Poluea $(a)$ iho la ilalo o Hale-auau; Ke kini ke kehau anu o Ka-lena. Akahi no ka nele o ka la pomaikai: Aohe moe-wa'a $(b)$ o ka po neiKa moe-wa'a, e!

\section{TRANSLATION}

Ka-ala, dewy and forest-clad, Bellies the plain at Ma-óha, As it slopes to the land below. The cool dew-fall comforts Ka-lena: First pinch this of want mid good luck No dream of canoe-voyage last night, No dream of disaster at sea.

The story of Cape Ka-ena, that finger-like thrusts itself out into the ocean from the western extremity of Oahu, touches Hawaiian mythology at many points: Its mountain eminence was a leina whane, jumping-off place, where the spirits of the deceased took their flying leap into ghost-land. Here it was that the demigod Mawi had his pou sto when he made the supreme effort of his life to align and unite the scattered group of islands; and here can still be seen Pohaku o Kauai, the one fragment of terra firma his hook could wrench from its base.




Culturally Responsive Geoscience Mural:

Art as Curriculum

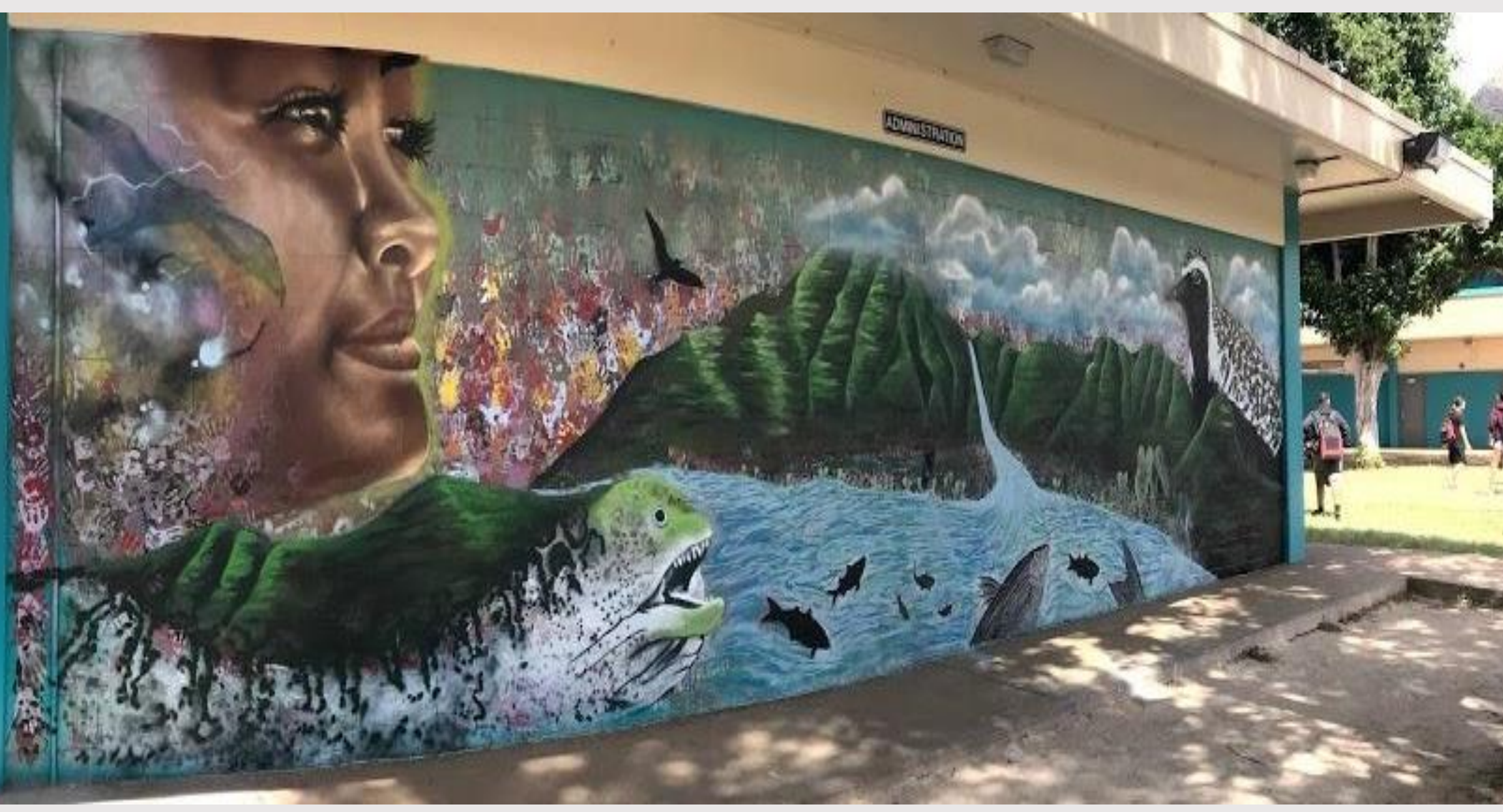

Wai 'anae Intermediate: Brigitte Russo's students read mo'olelo about Wai'anae to create a mural. Students' hand prints underly painting. 


\section{Comments from community}

- "We are letting everybody know that Wai'anae is not the bottom of the barrel, we have pride, we are not the stereotypes they say we are." - Security Guard

"My kid came home and told me about the mo'olelo in our ahupua'a; I wish I had those opportunities when I was in school." - Parent

"Thank you ... what a better way to instill pride of our culture, community, and campus to our students." - Teacher

"I can't wait to share the mo'olelo in this mural with my kids and grandkids. I hope this stays here forever." - Student 


\section{- "I still see my handprint." - Student}

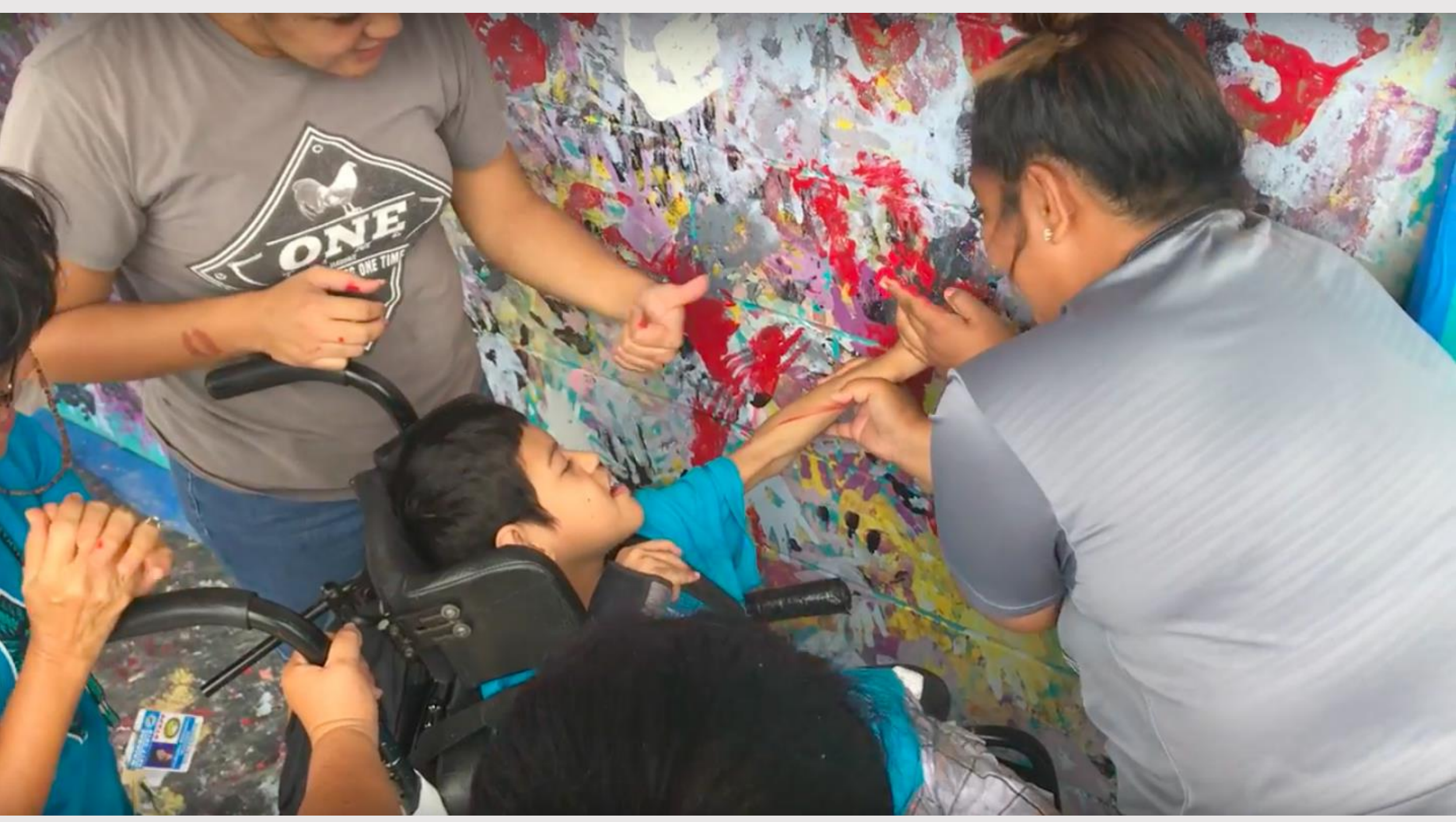




\section{Interest Survey Data, 5 Point Likert Scale: Left Native Hawaiian, Right Not Native Hawaiian}

Interest Survey 2015-2016

4.5

4.25

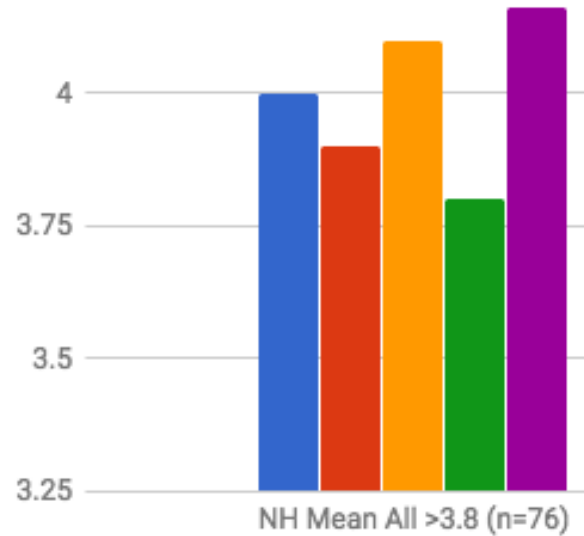

\section{Interest}

1. Interested in participating in service projects through school or community activities or on my own.

2. Interested in taking science, technology, engineering, and math courses... in High School, In College

3. Interested in taking Hawailan language and/or Hawailan studies courses... in High school, In College

\section{Interested in work and careers related to sustainability}

5. Interested in work and careers related to Hawailan culture and language. 


\section{Na Hopena A'o Data}

\section{Na Hopena A`o Survey}

$$
4.5
$$

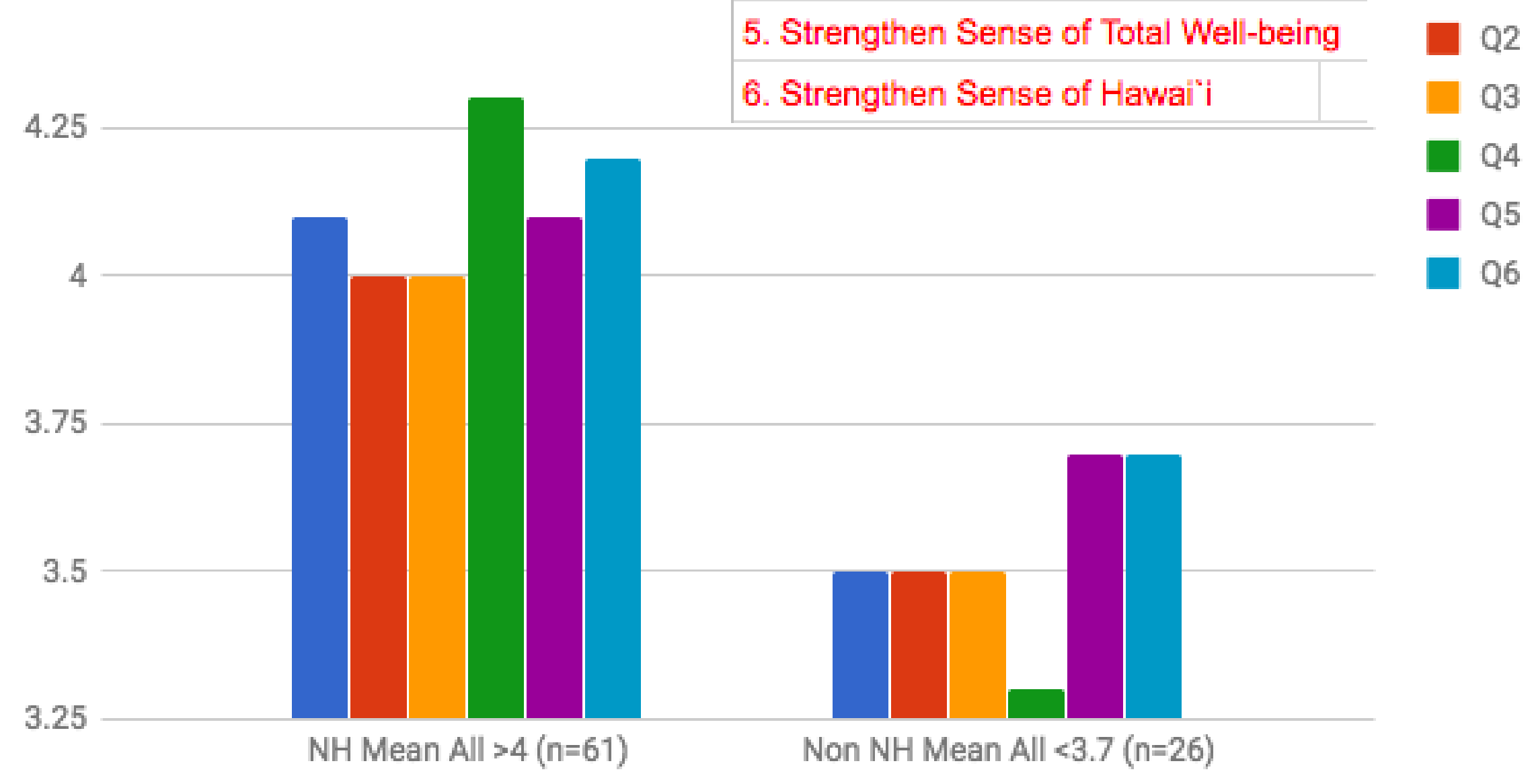

$\mathrm{Na} \mathrm{Hopena} \mathrm{A}^{\circ} \mathrm{o}$

1. Strengthen Sense of Belonging

2. Strengthen Sense of Responsibility

3. Strengthen Sense of Excellence

4. Strengthen Sense of Aloha

口 Q1

5. Strengthen Sense of Total Well-being

Non NH Mean All $<3.7(n=26)$ 


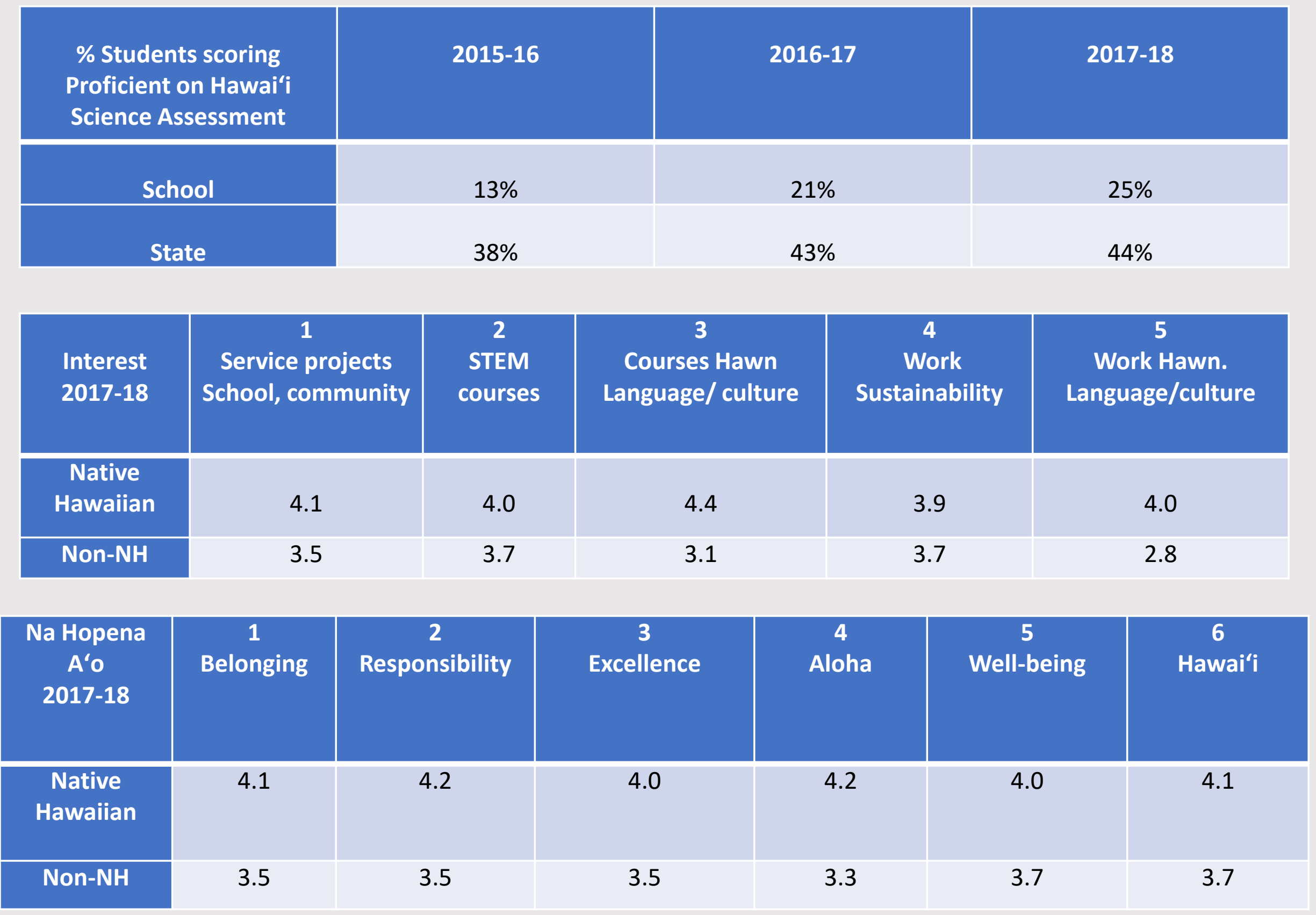




\section{Findings}

Teacher agency and capacity building:

- Find community partners

- Form school teams

- Gain expertise in science, culture, place

- Value social \& ecological justice

- Complete or enter programs: $8 \mathrm{MEd}, 8$ $\mathrm{PhD} / \mathrm{EdD}$

\section{Barriers}

- Cost and time restrictions of buses for field trips

- Weak school support

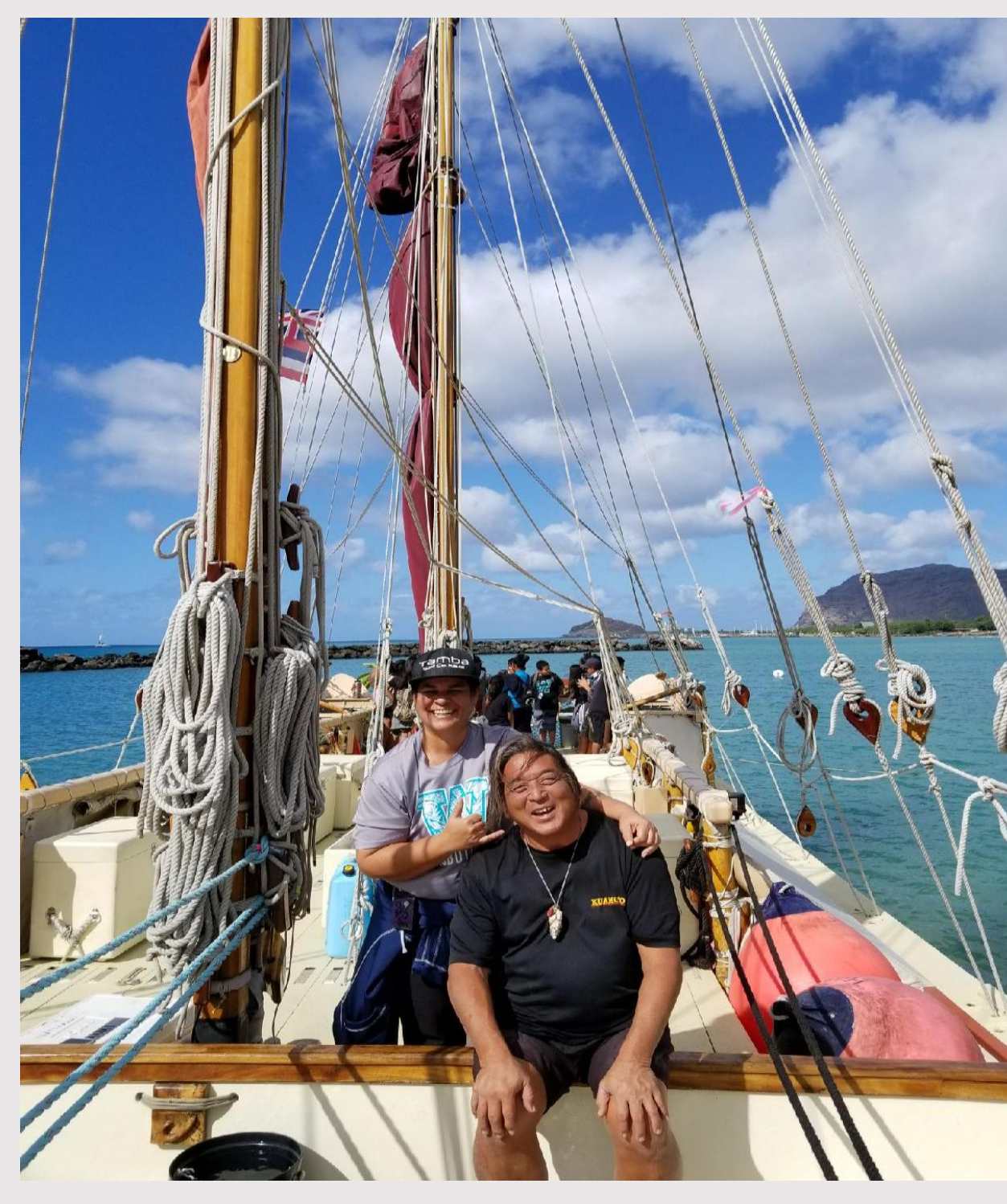

Matt and Kekaha on board Hōkūle'a Matt: Polynesian Voyaging Crewmember, peer teacher leader. 


\section{CONCLUSION:}

Teachers: Transformed content and pedagogy, indigenized, collaborated, partnered, involved students \& community Students: Higher interest in STEM, language, culture, Nā Hopena A'o and academic outcomes,

School: Attendance rose $62 \%$ to $70 \%$ from 2015 to 2017 Community: Engaged, supportive

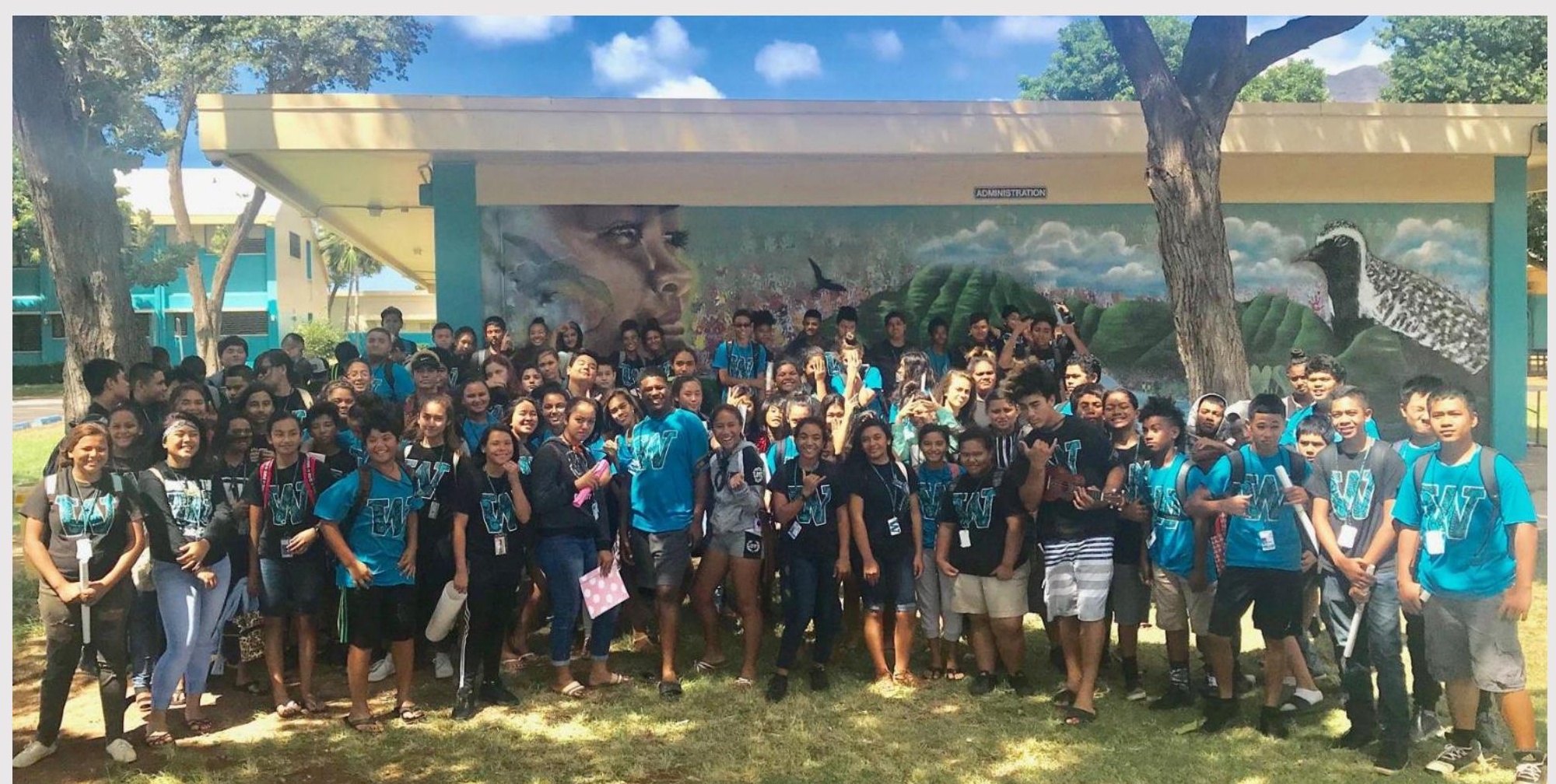




\section{MAHALO NUI LOA, THANK YOU VERY MUCH}

\section{QUESTIONS?}

Pauline W. U. Chinn, chinn@hawaii.edu

"Exploring Ways to Transform Teaching Practices to Increase Native Hawaiian Students' Interest in STEM," NSF Award No. 1551502

Thanks to Kekaha Spencer, Brigitte Russo, students, teachers, partners, administrators at Wai'anae Intermediate School.

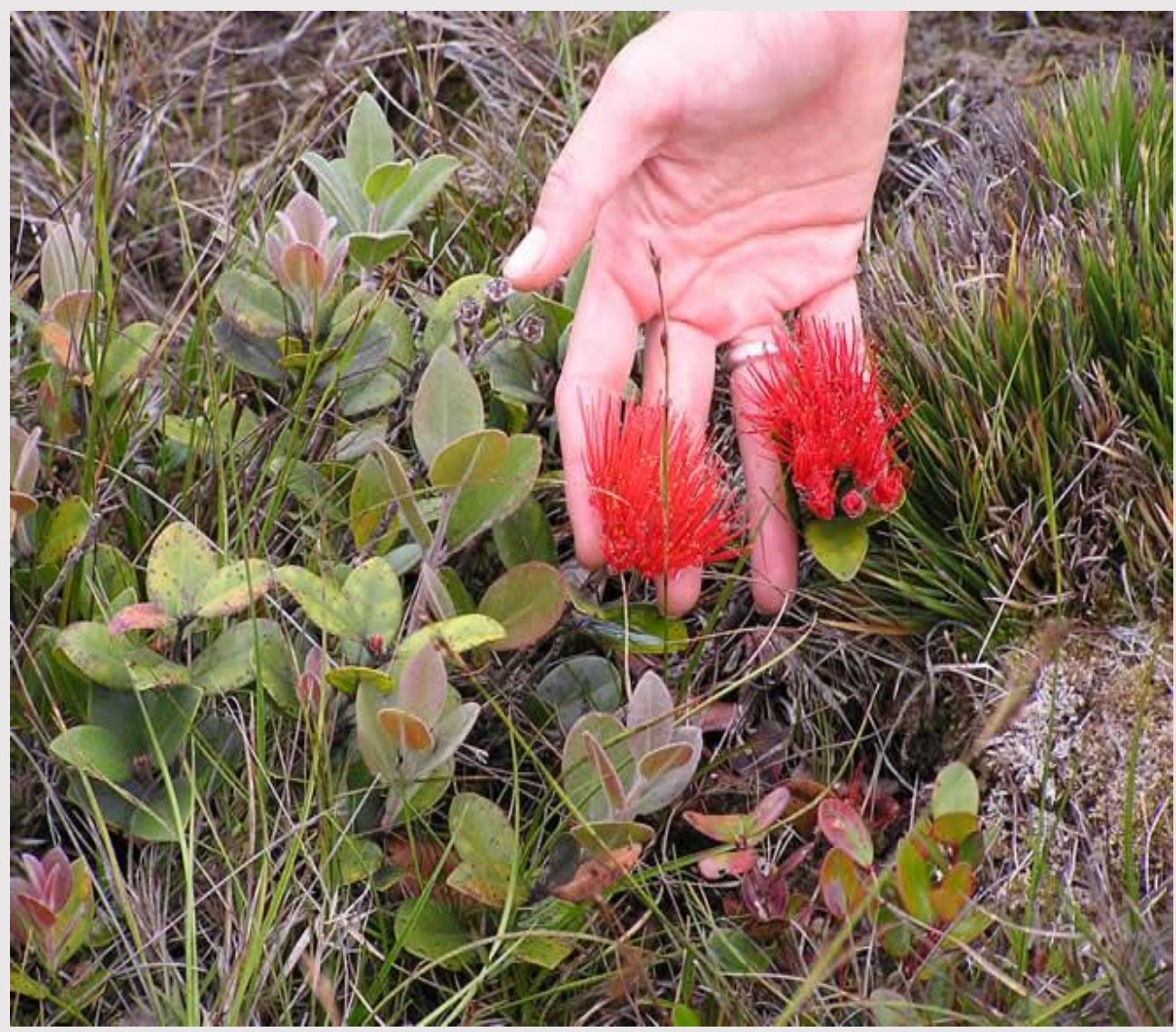

Dwarf 'ōhi'a lehua, Wai'aleale Bog, Kaua'i, P. Chinn 


\section{Selected References}

1. Pacific Rim Conservation (n.d.). Bird translocations. Retrieved from https://pacificrimconservation.org/our-work/management/bird-translocations/

2. Hawai'i State Department of Education (2015, November). Nā Hopena A'o Statements. Retrieved from www.hawaiipublicschools.org/DOE\%20Forms/NaHopenaAoE3.pdf

3. Lakoff, G. \& Johnson, M. (2003). Metaphors we live by. London: University of Chicago Press.

4. Moll, L.C., Amanti, C., Neff, D., \& Gonzalez, N. (1992). Funds of Knowledge for Teaching: Using a Qualitative Approach to Connect Homes and Classrooms. Theory into Practice, Qualitative Issues in Educational Research, 31, 2, 132-141.

5. National Center for Education Statistics (2011, Dec.). Comparing the Achievement Patterns of Native Hawaiian and Non-Native Hawaiian Grade 8 Students in Reading and Math. Retrieved from http://ies.ed.gov/ncee/edlabs/regions/pacific/pdf/REL 2012120.pdf

6. NGSS (2013). Appendix G. Crosscutting Concepts. Retrieved from http://www.nextgenscience.org/sites/default/files/Appendix\%20G\%20\%20Crosscutting\%20Concepts\%20FINAL\%20edited\%204.10.13.pdf

7. Sewell, W. Jr. (1992). A Theory of Structure: Duality, Agency, and Transformation. American Journal of Sociology, 98, 1, 1-29. 